\title{
Electroacupuncture for thalidomide/ bortezomib-induced peripheral neuropathy in multiple myeloma: a feasibility study
}

M Kay Garcia', Lorenzo Cohen ${ }^{1}$, Ying Guo ${ }^{2}$, Yuhong Zhou ${ }^{3}$, Bing You ${ }^{4}$, Joseph Chiang ${ }^{5}$, Robert Z Orlowski ${ }^{6,7}$, Donna Weber ${ }^{6}$, Jatin Shah ${ }^{6}$, Raymond Alexanian ${ }^{6}$, Sheeba Thomas ${ }^{6}$, Jorge Romaguera ${ }^{6}$, Liang Zhang ${ }^{6}$, Maria Badillo ${ }^{6}$, Yiming Chen ${ }^{6}$, Qi Wei ${ }^{1}$, Richard Lee ${ }^{1}$, Kay Delasalle ${ }^{6}$, Vivian Green ${ }^{6}$ and Michael Wang ${ }^{6 *}$

\begin{abstract}
Background: This single-arm study evaluated feasibility, safety, and initial efficacy of electroacupuncture for thalidomide/ bortezomib-induced peripheral neuropathy (PN) in cancer patients with multiple myeloma.

Methods: Patients with neuropathy $\geq$ grade 2 received 20 acupuncture treatments over 9 weeks.

Results: For the 19 evaluable patients, Functional Assessment of Cancer Therapy/Gynecological Oncology Group-Neurotoxicity (FACT/GOG/NTX) mean (SD) scores improved significantly between baseline and week 13 (20.8 [9.6] vs 13.2 [8.5], $p=0.0002$ ). Moderate effect size differences began on week 4, with the largest effect size differences found at week 9 for FACT/GOG/NTX scores, worst pain in the last 24 hours, and pain severity (Cohen's $d=1.43,1.19$, and 1.08, respectively) and continuing through week 13 (Cohen's $d=0.86,0.88$, and 0.90, respectively). From baseline to week 13, additional significant improvements were seen as follows: postural stability (1.0 [0.6] vs 0.8 [0.4], $p=0.02$ ); coin test (10.0 [7.4] vs 5.6 [1.9], $p<0.0001$ ); button test (96.1 [144.4] vs 54.9 [47.3], $p<0.0001$ ); and walking test (21.6 [10.0] vs $17.2[7.7], p=0.0003)$. No significant changes were seen with NCS.
\end{abstract}

Conclusions: Acupuncture may help patients experiencing thalidomide- or bortezomib-induced PN. Larger, randomized, clinical trials are needed.

Trial registration: ClinicalTrials.gov Identifier: NCT00891618.

Keywords: Acupuncture, Myeloma, Chemotherapy, Peripheral neuropathy, Integrative medicine

\section{Background}

Peripheral neuropathy $(\mathrm{PN})$ is a common side effect of treatment for patients with multiple myeloma (MM) [1,2]. $\mathrm{PN}$ is often chronic and can cause severe and debilitating symptoms that negatively affect patients' quality of life $[3,4]$. Thalidomide and bortezomib are remarkably effective in the treatment of MM [5,6], but studies have shown that up to $75 \%$ of patients treated with thalidomide [7-9] and one third to one half of patients treated with bortezomib [3,8-10] experience PN severe enough to require dose reduction or early termination of chemotherapy.

\footnotetext{
* Correspondence: miwang@mdanderson.org

${ }^{6}$ Department of Lymphoma/Myeloma, The University of Texas MD Anderson Cancer Center, 1515 Holcombe Boulevard, Unit 0429, Houston, Texas 77030, USA

Full list of author information is available at the end of the article
}

The pathogenesis underlying both bortezomib- and thalidomide-induced PN is unclear. For bortezomibinduced PN, previous studies have reported metabolic changes due to the accumulation of bortezomib in the dorsal root ganglia cells, mitochondrial-mediated dysregulation of $\mathrm{Ca}^{2+}$ homeostasis, and dysregulation of neurotrophins [10]. For thalidomide-induced PN, Johnson and colleagues found the risk of developing PN can be mediated by polymorphisms in genes that are involved in repair mechanisms and inflammation in the peripheral nervous system [11]. Overall, both agents cause significant neurotoxicity. Persistent or intermittent pain, paresthesia, and hyperaesthesia are common in patients with $\mathrm{PN}$, and many patients experience serious problems with gait and balance.

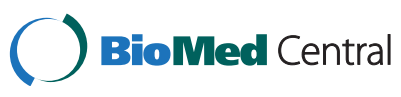

(c) 2014 Garcia et al.; licensee BioMed Central Ltd. This is an Open Access article distributed under the terms of the Creative Commons Attribution License (http://creativecommons.org/licenses/by/2.0), which permits unrestricted use, distribution, and reproduction in any medium, provided the original work is properly credited. The Creative Commons Public Domain Dedication waiver (http://creativecommons.org/publicdomain/zero/1.0/) applies to the data made available in this article, unless otherwise stated 
The current management of chemotherapy-induced PN focuses on treating its symptoms, generally with antidepressants, non-narcotic and narcotic analgesics, and anticonvulsants $[1,8,9]$. The efficacy of these treatment approaches is limited $[1,8,9]$, and the side effects may be severe. In contrast, acupuncture is a safe, minimally invasive procedure with few side-effects [12-14]. Very rare, sporadic, single cases of injury have been reported [15-17] and are usually due to negligence on the part of the practitioner rather than to the treatment itself. Although studies have shown that acupuncture may be helpful for managing neuropathic pain in patients with HIV/ AIDS [18,19] and diabetes [20-24], few studies [25-28] have evaluated its use in chemotherapy-induced PN.

Acupuncture analgesia involves the integration of multiple processes at different levels of the nervous system [29]. Manual acupuncture has been shown to activate $\mathrm{A} \beta-, \mathrm{A} \delta$ - and $\mathrm{C}$ afferent fibers, and when treatment intensity is supplemented by adding an electrical current to the needles, excitation of $\mathrm{A} \beta$ - and part of $\mathrm{A} \delta$-fibers can enhance analgesic effects [29]. After the acupuncture treatment signal ascends through the spinal ventrolateral funiculus, a complex network of brain regions, such as the nucleus raphe magnus, periaqueductal grey, locus coeruleus, arcuate nucles, preoptic area, nucleus submedius, habenular nucleus, accumbens nucleus, caudate nucleus, septal area, amygdala, and sensorymotor cortex, become involved in signal processing [29].

Inherited genetic factors also play a role in individual response to acupuncture, and multiple molecules, such as opioid peptides ( $\mu-, \delta$-, and $\mathrm{K}$-receptors), glutamate (NMDA and AMPA/KA receptors), 5-hydroxytryptamine, and cholecystokinin octapeptide, help mediate analgesia [29]. The release of opioid peptides evoked by electroacupuncture depends on the frequency of current delivered [30]. For example, a frequency of $2 \mathrm{~Hz}$ induces the gene expression of endorphins in the diencephalons, 2-15 Hz causes the release of endorphins and enkephalin in the brain and dynorphin in the spinal cord, and a frequency of $100 \mathrm{~Hz}$ causes the release of dynorphin in the spinal cord alone [30]. When alternating frequencies are used, these three opioids have a synergistic effect [31].

On the basis of promising findings from earlier studies [19-25,27,28,32], we designed the current trial to evaluate the feasibility, safety, and initial efficacy of acupuncture for the treatment of thalidomide- and/or bortezomibinduced chronic PN in patients with MM. Results from this study will help inform the design of a future, large randomized clinical trial.

\section{Results}

Participant flow throughout the study is shown in Figure 1. Of 27 patients who met eligibility, all agreed to participate. Eight patients (30\%) were lost to follow-up for the

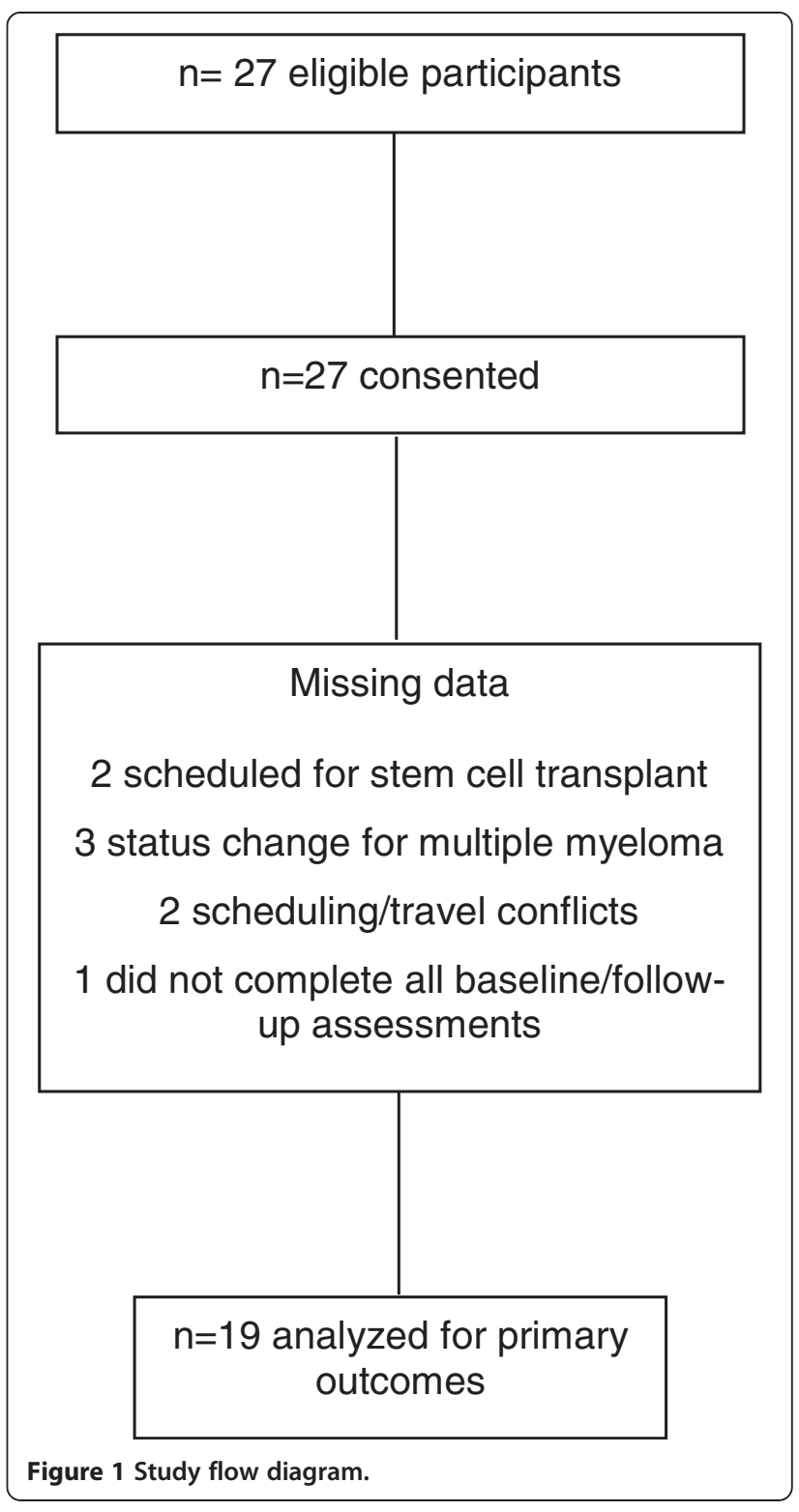

following reasons: disease progression (relapsed MM, $\mathrm{n}=3)$, scheduled stem cell transplantation $(\mathrm{n}=2)$, scheduling/travel conflicts $(\mathrm{n}=2)$, and failure to complete follow-up assessments $(n=1)$. Nineteen patients were evaluable for study analyses. No serious adverse events related to acupuncture were reported; however, one patient did describe a worsening of peripheral neuropathy symptoms during the study.

\section{Patient characteristics}

Patient characteristics are provided in Table 1. Fourteen men and five women participated, and the mean participant age was 64 years (range, 46-79 years). Thirteen (68\%) patients had grade 2 and six (32\%) patients had grade 3 PN. All patients had sensory neuropathy, and one had combined sensory and motor symptoms. All 
Table 1 Patient characteristics

\begin{tabular}{|c|c|}
\hline \multicolumn{2}{|c|}{ Characteristics } \\
\hline Mean age, years (range) & 64 (range 46-79) \\
\hline & No. of patients (\%) \\
\hline \multicolumn{2}{|l|}{ Gender } \\
\hline Men & $14(74 \%)$ \\
\hline Women & $5(26 \%)$ \\
\hline \multicolumn{2}{|l|}{ Diagnosis } \\
\hline Multiple myeloma & $18(95 \%)$ \\
\hline Amyloidosis & $1(5 \%)$ \\
\hline \multicolumn{2}{|l|}{ Peripheral Neuropathy (PN) } \\
\hline Grade 2 & $13(68 \%)$ \\
\hline Grade 3 & $6(32 \%)$ \\
\hline \multicolumn{2}{|l|}{ PN Treatment } \\
\hline Pregabalin & $11(58 \%)$ \\
\hline Gabapentin & $6(32 \%)$ \\
\hline None & $2(10 \%)$ \\
\hline \multicolumn{2}{|l|}{ Pain Management* } \\
\hline Hydrocodone & $4(21 \%)$ \\
\hline Oxycodone & $3(16 \%)$ \\
\hline Morphine & $1(5 \%)$ \\
\hline Hydromorphone + bupivacaine (pump) & $1(5 \%)$ \\
\hline \multicolumn{2}{|l|}{ Prior Therapy } \\
\hline Bortezomib & $16(84 \%)$ \\
\hline Thalidomide & $3(16 \%)$ \\
\hline \multicolumn{2}{|l|}{ Dose of Prior Therapy } \\
\hline Bortezomib, mg (range) & $31.7(10.5-64)$ \\
\hline Thalidomide, g (range) & $84.7(8.4-163)$ \\
\hline No. Months Since Last Dose (range) & $9.8(0.75-41.5)$ \\
\hline
\end{tabular}

*Patients had to remain on same treatment regimen; however, minor adjustments in dosage were allowed.

patients had symptoms in both the upper and lower extremities. Sixteen (84\%) patients had been treated with bortezomib and three (16\%) with thalidomide. The average number of months since the patients received their last doses of thalidomide and/or bortezomib was 9.8 (range, 0.75 to 41.5 months).

For neuropathy symptoms, $11(58 \%)$ patients took pregabalin, and six $(32 \%)$ took gabapentin during the study. For pain control, four (21\%) patients took hydrocodone, three (16\%) oxycodone, one (5\%) morphine, and one $(5 \%)$ hydromorphone. Two (10\%) patients did not take opioids, pregabalin, or gabapentin for symptom management during the study.

\section{Efficacy}

Patient reported outcomes (PROs) are provided in Table 2. For the Functional Assessment of Cancer Therapy/Gynecological Oncology Group-Neurotoxicity scale (FACT/GOG/NTX), there was a main effect of time $(\mathrm{p}<0.0001)$. The mean (standard deviation $[\mathrm{SD}])$ scores improved significantly between baseline (20.8 [9.6]) and all subsequent time points: week 4: 16.7 (9.4), $\mathrm{p}=0.02$; week 9: 9.9 (5.6), $\mathrm{p}<0.0001$; and week 13:13.2 (8.5), $\mathrm{p}=0.0002$. A moderate effect size (Table 3) was found by week 4 (Cohen's $d=0.4$ ), with the largest effect size occurring between baseline and week 9 (Cohen's $d=1.4$ ). The effect size remained large at the one-month follow-up visit at week 13 (Cohen's $d=0.9$ ).

For Brief Pain Inventory-Short Form (BPI-SF) scores, there was a main effect of time for all subscales (all p's $<0.0001)$. Mean (SD) scores revealed significant improvements in pain severity and interference and worst pain in 24 hours at all time points (Table 2), with large effect size differences (Table 3 ) found for both pain severity (week $9=1.1$ and week $13=0.9$ ) and worst pain in 24 hours (week $4=0.8$; week $9=1.2$; and week $13=0.9$ ). For pain interference, Cohen's $d$ effect size estimates were moderate (week $4=0.4$; week $9=0.6$, and week $13=0.5$ ).

The Functional Assessment of Cancer Therapy-General (FACT-G) scores revealed significant main effect of time for the physical well-being scale $(\mathrm{p}=0.0004)$ with improvement from baseline to the end of treatment at week 9 (9.2 [6.1] vs $5.0[3.8], \mathrm{p}<0.05)$ and from baseline to follow-up at week $13(9.2[6.1]$ vs $5.5[4.3, \mathrm{p}=0.01)$. No improvements were seen in social/family, emotional, or functional well-being (Table 2).

Timed-function test scores improved from baseline to one-month follow-up as follows: coin test (10.0 [7.4] vs 5.6 [1.9], $\mathrm{p}<0.0001)$; button test $(96.1$ [144.4] vs 54.9 [47.3], $\mathrm{p}<0.0001)$; walking test (21.6 [10.0] vs 17.2 [7.7], $\mathrm{p}=0.0003)$; and postural stability $(1.0[0.6]$ vs $0.8[0.4]$, $\mathrm{p}=0.02)$. Marginal improvement was seen in fall risk, but it was not statistically significant (Table 4). No significant changes were found for the nerve conduction studies (NCS data not shown).

\section{Discussion}

With an extended treatment period lasting 9 weeks and involving 20 acupuncture sessions at two to three times per week, our criteria for feasibility were that at least half of the patients approached would agree to participate and that the drop-out rate would be less than one third. In this single-arm trial, all patients who were referred to the research nurse and determined to be eligible agreed to participate, and the drop-out rate was $30 \%(8 / 27)$; thus, the acupuncture service provided was feasible.

In terms of determining initial efficacy, the PRO scores indicated significant improvement in $\mathrm{PN}$ symptoms starting at week 4 (Cohen's $d=0.4 ; \mathrm{p}=0.02$ ), with the largest improvement seen at the end of treatment at week 9 (Cohen's $d=1.4 ; \mathrm{p}<0.0001$ ) and remaining 
Table 2 Patient-reported outcomes (PROs)

\begin{tabular}{|c|c|c|c|c|c|c|}
\hline \multirow[t]{2}{*}{ Measure } & \multirow{2}{*}{$\begin{array}{l}\text { Time } \\
\text { point }\end{array}$} & \multirow[t]{2}{*}{$\mathbf{n}$} & \multirow{2}{*}{$\begin{array}{l}\text { Mean } \\
(S D)\end{array}$} & \multicolumn{2}{|r|}{$p$ value } & \multirow{2}{*}{$\begin{array}{c}\mathrm{p} \text { value } \\
\text { Mixed model analysis* }\end{array}$} \\
\hline & & & & Paired $t$ test & Non-parametric signed rank test & \\
\hline \multirow[t]{4}{*}{ FACT/GOG-NTX ${ }^{\dagger}$} & Baseline & 19 & $20.8(9.6)$ & - & - & - \\
\hline & 4 weeks & 18 & $16.7(9.4)$ & 0.0114 & 0.018 & 0.0263 \\
\hline & 9 weeks & 15 & $9.9(5.6)$ & 0.0009 & $<0.0001$ & $<0.0001$ \\
\hline & 13 weeks & 15 & $13.2(8.5)$ & 0.0007 & $<0.0002$ & $<0.0001$ \\
\hline \multicolumn{7}{|l|}{ BPI-SF $^{\ddagger}$} \\
\hline Pain & Baseline & 18 & $25.4(18.5)$ & - & - & - \\
\hline \multirow[t]{3}{*}{ severity } & 4 weeks & 18 & $18.2(16.4)$ & 0.0048 & 0.0052 & 0.0056 \\
\hline & 9 weeks & 16 & $15.1(14.5)$ & 0.0004 & 0.0001 & $<0.0001$ \\
\hline & 13 weeks & 16 & $17.6(16.6)$ & 0.004 & 0.0007 & $<0.0001$ \\
\hline Pain & Baseline & 18 & $25.4(18.5)$ & - & - & - \\
\hline \multirow[t]{3}{*}{ interference } & 4 weeks & 18 & $18.2(16.4)$ & 0.0048 & 0.0052 & 0.0056 \\
\hline & 9 weeks & 16 & $15.1(14.5)$ & 0.0004 & 0.0001 & $<0.0001$ \\
\hline & 13 weeks & 16 & 17.6 (16.6) & 0.004 & 0.0007 & $<0.0001$ \\
\hline Worst pain in & Baseline & 18 & $6.2(3.5)$ & - & - & - \\
\hline \multirow[t]{3}{*}{ last 24 hours } & 4 weeks & 18 & $3.8(2.7)$ & 0.0057 & 0.0049 & 0.0004 \\
\hline & 9 weeks & 16 & $2.9(2.1)$ & $<0.0001$ & 0.0002 & $<0.0001$ \\
\hline & 13 weeks & 15 & $3.6(2.5)$ & $<0.0001$ & 0.0006 & $<0.0001$ \\
\hline \multicolumn{7}{|l|}{ FACT-G ${ }^{\S}$} \\
\hline Physical & Baseline & 18 & $9.2(6.1)$ & - & - & - \\
\hline \multirow[t]{3}{*}{ Well-being } & 4 weeks & 18 & $7.2(5.6)$ & 0.3 & 0.4 & 0.3 \\
\hline & 9 weeks & 14 & $5.0(3.8)$ & $<0.05$ & 0.02 & 0.002 \\
\hline & 13 weeks & 16 & $5.5(4.3)$ & 0.01 & 0.002 & 0.0004 \\
\hline Social/family & Baseline & 19 & $20.5(6.3)$ & - & - & - \\
\hline \multirow[t]{3}{*}{ Well-being } & 4 weeks & 16 & $19.7(6.3)$ & 0.7 & 0.8 & 0.4 \\
\hline & 9 weeks & 14 & $19.4(8.5)$ & 0.3 & 0.7 & 0.1 \\
\hline & 13 weeks & 15 & $19.6(7.0)$ & 0.3 & 0.6 & 0.3 \\
\hline Emotional & Baseline & 19 & $5.3(5.5)$ & - & - & - \\
\hline \multirow[t]{3}{*}{ Well-being } & 4 weeks & 18 & $4.4(4.0)$ & 0.5 & 0.6 & 0.5 \\
\hline & 9 weeks & 16 & $3.8(4.3)$ & 0.4 & 0.3 & 0.2 \\
\hline & 1 month & 16 & 4.1 (3.9) & 0.3 & 0.4 & 0.2 \\
\hline Functional & Baseline & 19 & $20.8(6.7)$ & - & - & - \\
\hline \multirow[t]{3}{*}{ Well-being } & 4 weeks & 17 & 19.7 (8.4) & 0.07 & 0.09 & $<0.05$ \\
\hline & 9 weeks & 14 & $19.6(7.0)$ & 0.1 & 0.1 & 0.1 \\
\hline & 1 month & 15 & $20.4(8.9)$ & 0.4 & 0.4 & 0.3 \\
\hline
\end{tabular}

*Mixed model analysis for time effect was performed for variables with four assessments.

${ }^{\dagger}$ Functional Assessment of Cancer Therapy/Gynecologic Oncology Group-Neurotoxicity Scale.

${ }^{\ddagger}$ Brief Pain Inventory - Short Form.

${ }^{\S}$ Functional Assessment of Cancer Therapy - General Scale.

through the one-month follow-up at week 13 (Cohen's $d=0.9 ; \mathrm{p}=0.0002$ ). Additionally, significant improvement was found for pain severity and interference and for worst pain experienced over 24 hours (see Tables 2 and 3). Again, these changes were seen by week 4 and persisted at the one-month follow-up.
Although this study will help inform future trials, there were several limitations. As a feasibility study, it was limited by a small sample size and lack of a comparison group. According to the United States Food and Drug Administration, however, assessment of "pain at its worst in the last 24 hours" on the BPI-SF is sufficient for 
Table 3 Cohen's $\boldsymbol{d}$ effect size estimates

\begin{tabular}{lccc}
\hline Measure & $\mathbf{n}$ & Mean (SD) Change from Baseline & Cohen's $\boldsymbol{d}$ \\
\hline FACT/GOG-NTX* & & $4.1(0.2)$ & 0.4 \\
Week 4 & 19 & $10.9(4.1)$ & 1.4 \\
Week 9 & 19 & $7.6(1.2)$ & 0.9 \\
Week 13 & 19 & & \\
BPI-SF $^{\dagger}$ & & $2.4(0.8)$ & \\
Worst pain & & $3.3(1.4)$ & 0.8 \\
Week 4 & 18 & $2.6(1.0)$ & 1.2 \\
Week 9 & 18 & & 0.9 \\
Week 13 & 18 & $7.1(3.4)$ & 0.7 \\
Severity & & $10.6(4.8)$ & 1.1 \\
Week 4 & 18 & $9.1(4.0)$ & 0.9 \\
Week 9 & 18 & & 0.4 \\
Week 13 & 18 & $7.2(2.1)$ & 0.6 \\
Interference & & $10.3(4.0)$ & 0.5 \\
Week 4 & 18 & $7.8(1.9)$ & \\
Week 9 & 18 & 18 &
\end{tabular}

*Functional Assessment of Cancer Therapy/Gynecologic Oncology Group-Neurotoxicity Scale.

${ }^{\dagger}$ Brief Pain Inventory - Short Form.

measuring a pain reduction treatment effect [33], and a reduction of 2 points or more on a $0-10$ numeric rating scale for "worst pain" in the last 24 hours implies a clinically significant change. A greater than 2 point mean reduction in pain from baseline was noted at each time point.

Another limitation was the inability to separate specific versus non-specific placebo effects of the acupuncture treatment. Clearly, there is a strong placebo component of acupuncture [34-36], and future sham-controlled trials are needed to parse-out various treatment elements. With this trial design, we cannot rule out the possibility of a placebo effect; however, participants had persistent PN in spite of having had previous treatment using standard of care methods, with which there would also have been expected benefit due to placebo. Finally, this study was limited by the fact that there was no long-term follow-up, and the extent to which symptoms returned is unknown. Future trials may need to include long-term treatment for maintenance of symptom relief.

\section{Conclusions}

Controlling chemotherapy-induced PN while managing an underlying hematologic malignancy presents many challenges [1]. Symptoms may be severe enough to require dose reduction or termination of chemotherapy. Often, symptoms become chronic and negatively impact patients' quality of life [3,4]. In this small, nonrandomized feasibility study, reductions in BPI-SF pain severity and interference as well as improvements in FACT/GOG/NTX scores and improvements in objective timed function tests provide compelling evidence that acupuncture may be of benefit as an adjunct to symptom management in chemotherapy-induced PN. Due to the dearth of literature in this area and the chronicity of debilitating symptoms, further investigation is warranted. Randomized, controlled trials with strong methodology to reduce risk of bias and parse-out specific versus non-specific effects are greatly needed.

\section{Methods}

\section{Study population}

Prior to activating this non-randomized pilot study, we obtained approval from the MD Anderson Cancer Center Institutional Review Board. Potential participants for this

Table 4 Timed function tests

\begin{tabular}{|c|c|c|c|c|c|}
\hline \multirow[t]{2}{*}{ Measure } & \multirow{2}{*}{$\begin{array}{l}\text { Time } \\
\text { point }\end{array}$} & \multirow[t]{2}{*}{$\mathrm{n}$} & \multirow[t]{2}{*}{ Mean (SD) } & \multicolumn{2}{|r|}{$\mathrm{p}$ value } \\
\hline & & & & Paired $t$ test & Non-parametric signed rank test \\
\hline \multicolumn{6}{|c|}{ Timed function tests* } \\
\hline \multirow[t]{2}{*}{ Walk test } & Baseline & 19 & $21.6(10)$ & - & - \\
\hline & 13 weeks & 19 & $17.2(7.7)$ & 0.0005 & 0.0003 \\
\hline \multirow[t]{2}{*}{ Button test } & Baseline & 19 & $96.1(144.4)$ & - & - \\
\hline & 13 weeks & 19 & $54.9(47.3)$ & 0.16 & $<0.0001$ \\
\hline \multirow[t]{2}{*}{ Coin test } & Baseline & 19 & $10.0(7.4)$ & - & - \\
\hline & 13 weeks & 19 & $5.6(1.9)$ & 0.0123 & $<0.0001$ \\
\hline \multicolumn{6}{|l|}{ Balance tests } \\
\hline \multirow[t]{2}{*}{ Postural stability } & Baseline & 19 & $1.0(0.6)$ & - & - \\
\hline & 13 weeks & 19 & $0.8(0.4)$ & 0.06 & 0.02 \\
\hline \multirow[t]{2}{*}{ Fall risk } & Baseline & 18 & $1.9(0.8)$ & - & - \\
\hline & 13 weeks & 18 & $1.6(0.6)$ & 0.06 & 0.07 \\
\hline
\end{tabular}

*In seconds. 
study were identified by faculty in the Department of Lymphoma/Myeloma at The University of Texas MD Anderson Cancer Center in Houston, Texas, and referred to the research nurse for assessment of eligibility and to obtain informed consent. Eligible participants were more than 18 years of age and had a diagnosis of MM. They had grade 2 or higher neuropathy according to the Common Terminology Criteria for Adverse Events, v3.0 [37] in spite of previous treatment with gabapentin, duloxetin, and/or pregabalin. Participants had to remain on the same medications throughout the study period; however, minor adjustments in dosage were allowed. An Eastern Co-operative Oncology Group Performance Status of $\leq 2$ was required for study inclusion.

Patients were excluded if they were currently being treated with thalidomide and/or bortezomib or if they had a local infection or deformities at or near the acupuncture sites. Additionally, patients were excluded for any of the following reasons: using alternative medicines that could affect PN symptoms, such as herbal agents, or taking high-dose vitamins; having known coagulopathy or taking heparin or warfarin; having platelets < $50000 / \mu \mathrm{L}$ or a white blood cell count $<3000 / \mu \mathrm{L}$; having active central nervous system disease, a pacemaker, mental incapacitation or a significant emotional or psychological disorder that could interfere with study participation; being pregnant or lactating; having a history of chronic alcohol misuse or diabetes- or HIVrelated PN; having prior acupuncture treatment for any indication within 30 days of enrollment; and receiving active treatment for MM.

\section{Study design and treatment}

The treatment methods (i.e., point selection, type of stimulation, needling techniques, and treatment schedule) were chosen by a panel of expert faculty from the American College of Acupuncture and Oriental Medicine in Houston. Patients received acupuncture three times per week for 4 weeks followed by 1 week off (week 5) and then twice per week for 4 more weeks (i.e., 20 treatments over 9 weeks). Two licensed staff acupuncturists with over 30 years combined experience, and who were trained in the same masters' degree program, provided all treatments.

Standardized techniques for locating points and depth of insertion were utilized [38,39] while patients were treated in a comfortable supine position. All treatments were given using needles (36-38 gauge and $30 \mathrm{~mm}$ length) manufactured by Seirin Corporation (Shizuoka, Japan). Bilateral upper and lower extremities were treated. The specific points selected for this trial were LI4, SI3, Baxie 2, Baxie 3, Lv3, Sp6, Gb42, St 36, Bafeng 2, Bafeng 3, Du 20, CV4, and CV6 (see Table 5). After de qi (a sensation of numbness, tingling, or warmth at the needle insertion site) was experienced by the patient, electrical stimulation was applied bilaterally as follows: from LI4 (negative) to SI3 (positive) and from Lv3 (negative) to Gb42 (positive) at 2$100 \mathrm{~Hz}$ for 20 minutes. All needles were then removed.

\section{Assessments}

To determine feasibility and safety, we tracked subject recruitment, attrition, compliance with treatment and follow-up regimens, and adverse events. Our criteria for success in terms of feasibility were that that at least 50\% of the patients approached would agree to participate and fewer than $33 \%$ of the patients who gave consent to participate would drop out after recruitment.

For efficacy, the FACT/GOG/NTX scale was used to assess the primary endpoint for $\mathrm{PN}$, and patients had to complete at least $80 \%$ of the treatment sessions to be

\section{Table 5 Acupuncture treatment}

\begin{tabular}{|c|c|c|c|c|}
\hline Points & Sides & Depth & Angle & $\overline{\text { Gauge }}$ \\
\hline $\operatorname{Lv} 3^{*}$ & $\times 2$ & $0.5-1 \mathrm{in}$. & perpendicular & 36 \\
\hline Sp 6 & $\times 2$ & $0.8-1$ in. & perpendicular & 36 \\
\hline Gb 42* & $\times 2$ & $0.5-1 \mathrm{in}$. & perpendicular & 36 \\
\hline St 36 & $\times 2$ & $1-1.5 \mathrm{in}$. & perpendicular & 36 \\
\hline $\mathrm{LI} 4^{*}$ & $\times 2$ & $0.5-1 \mathrm{in}$ & perpendicular & 36 \\
\hline $\mathrm{SI} 3^{*}$ & $\times 2$ & $0.5-1 \mathrm{in}$. & perpendicular & 36 \\
\hline CV 4 & midline & $0.5-1 \mathrm{in}$. & perpendicular & 36 \\
\hline CV 6 & midline & $0.5-1 \mathrm{in}$. & perpendicular & 36 \\
\hline Du 20 (posterior direction against channel flow) & midline & $0.8-1 \mathrm{in}$ & perpendicular & 36 \\
\hline Baxie 2 \& 3 (between 2 nd \& 3rd and 3rd \& 4th fingers) ${ }^{\dagger}$ & $\times 2$ & $0.5-1 \mathrm{in}$. & Horizontal (towards the wrist) & 36 \\
\hline Bafeng $2 \& 3$ (between 2 nd \& 3 rd and $3 r d \& 4$ th toes) ${ }^{\dagger}$ & $\times 2$ & $0.5-1 \mathrm{in}$ & Oblique (towards the heel) & 36 \\
\hline
\end{tabular}

*After de qi was detected, electrical stimulation was applied using an electro-acupuncture stimulator (IC-1107, ITO Co., LTD, Tokyo, Japan) at alternating frequencies $(2-100 \mathrm{~Hz})$ as follows: pair one-Lv3 negative, Gb 42 positive; pair two-LI 4 negative, SI 3 positive. Voltage was adjusted to patient tolerance (ie., able to feel strong stimulation without pain).

${ }^{\dagger}$ Thumb and great toe are considered 1st digit. 
evaluable. The FACT-G survey and the Brief Pain Inventory-Short Form (BPI-SF) were also used to evaluate PROs. For objective outcomes, timed function tests (i.e., the coin test, button test, walking test, and postural stability/fall risk) and NCS were performed. The NCS consisted of bilateral radial and sural sensory nerve conduction and bilateral tibial motor nerve conduction tests. We used previously established age-adjusted values to categorize sensory and motor nerve action potential amplitudes as normal or abnormal [40].

\section{Statistical considerations}

Patient characteristics were assessed by frequency distributions, means, and ranges for relevant variables. For PROs, mean values/scores were calculated at baseline and weeks 4, 9, and 13 and compared for statistical significance. For variables with four time points, mixed model analyses were performed for time effect. Changes in function tests and NCS were compared from baseline to week 13. All comparisons were made using the paired Student's $t$-test as well as the non-parametric signed rank test. Finally, in order to determine the strength of change due to the intervention, Cohen's $d$ effect size estimates were calculated for both the pain and neuropathy scores. Statistical analyses were performed using SPSS, v20 statistical software (IBM Corporation, Armonk, NY).

\section{Competing interests}

The authors declare that they have no competing interests.

\section{Authors' contributions}

All authors participated in approval of the final manuscript. MW obtained funding and was responsible for overseeing all aspects of the study. MG, LC, $Y G, M B, Y C$, and $Q W$ participated in data collection, management, analysis, and interpretation. $Z Y, Y B, J C, R O, D W, J S, R A, S T, J R, R L, L Z, K D$, and VG provided expertise during study development, design, data collection, interpretation, and writing of the manuscript.

\section{Authors' information}

M. Kay Garcia and Lorenzo Cohen are co-first authors.

\section{Acknowledgements}

Funding for this study was provided in part by Millennium Pharmaceuticals, Inc. and Marvin Kimmel Research Funds at MD Anderson Cancer Center. We would also like to thank Dawn Chalaire and the Department of Scientific Publications, The University of Texas MD Anderson Cancer Center for helpful editorial comments on this article. RO would like to acknowledge support from the National Cancer Institute (P50 CA142509 and U10 CA032102).

\footnotetext{
Author details

${ }^{1}$ Integrative Medicine Program, The University of Texas MD Anderson Cancer Center, 1515 Holcombe Boulevard, Unit 0462, Houston, Texas 77030, USA. ${ }^{2}$ Department of Rehabilitation Medicine, The University of Texas MD Anderson Cancer Center, 1515 Holcombe Boulevard, Unit 1414, Houston, Texas 77030, USA. ${ }^{3}$ Department of Medical Oncology, Zhongshan Hospital, Fudan University, 180 Feng Lin Road, Shanghai, P.R. China. ${ }^{4}$ American College of Acupuncture and Oriental Medicine, 9100 Park West Drive, Houston, Texas 77063, USA. ${ }^{5}$ Department of Anesthesiology \& Peri-Operative Medicine, The University of Texas MD Anderson Cancer Center, 1515 Holcombe Boulevard, Unit 0409, Houston, Texas 77030, USA. ${ }^{\circ}$ Department of Lymphoma/Myeloma, The University of Texas MD Anderson Cancer Center, 1515 Holcombe Boulevard, Unit 0429, Houston, Texas 77030, USA. Department of Experimental
}

Therapeutics, The University of Texas MD Anderson Cancer Center, 1515 Holcombe Boulevard, Houston, Texas 77030, USA.

Received: 14 November 2013 Accepted: 9 April 2014 Published: 9 May 2014

\section{References}

1. Richardson PG, Delforge M, Beksac M, Wen P, Jongen JL, Sezer O, Terpos E, Munshi N, Palumbo A, Rajkumar SV, Harousseau JL, Moreau P, Avet-Loiseau H, Lee JH, Cavo M, Merlini G, Voorhees P, Chng WJ, Mazumder A, Usmani S, Einsele H, Comenzo R, Orlowski R, Vesole D, Lahuerta JJ, Niesvizky R, Siegel D, Mateos MV, Dimopoulos M, Lonial S, et al: Management of treatmentemergent peripheral neuropathy in multiple myeloma. Leukemia 2012, 26(4):595-608.

2. Richardson PG, Weller E, Lonial S, Jakubowiak AJ, Jagannath S, Raje NS, Avigan DE, Xie W, Ghobrial IM, Schlossman RL, Mazumder A, Munshi NC, Vesole DH, Joyce R, Kaufman JL, Doss D, Warren DL, Lunde LE, Kaster S, Delaney C, Hideshima T, Mitsiades CS, Knight R, Esseltine DL, Anderson KC: Lenalidomide, bortezomib, and dexamethasone combination therapy in patients with newly diagnosed multiple myeloma. Blood 2010, 116(5):679-686.

3. Velasco R, Petit J, Clapes V, Verdu E, Navarro X, Bruna J: Neurological monitoring reduces the incidence of bortezomib-induced peripheral neuropathy in multiple myeloma patients. J Peripher Nerv Syst 2010, 15(1):17-25

4. Raab MS, Podar K, Breitkreutz I, Richardson PG, Anderson KC: Multiple myeloma. Lancet 2009, 374(9686):324-339.

5. Kaufmann $H$, Raderer M, Wohrer S, Puspok A, Bankier A, Zielinski C, Chott A, Drach J: Antitumor activity of rituximab plus thalidomide in patients with relapsed/refractory mantle cell lymphoma. Blood 2004, 104(8):2269-2271.

6. Cavo M, Pantani L, Petrucci MT, Patriarca F, Zamagni E, Donnarumma D, Crippa C, Boccadoro M, Perrone G, Falcone A, Nozzoli C, Zambello R, Masini L, Furlan A, Brioli A, Derudas D, Ballanti S, Dessanti ML, De Stefano V, Carella AM, Marcatti M, Nozza A, Ferrara F, Callea V, Califano C, Pezzi A, Baraldi A, Grasso M, Musto P, Palumbo A: Bortezomib-thalidomide-dexamethasone is superior to thalidomide-dexamethasone as consolidation therapy after autologous hematopoietic stem cell transplantation in patients with newly diagnosed multiple myeloma. Blood 2012, 120(1):9-19.

7. Umapathi T, Chaudhry V: Toxic neuropathy. Curr Opin Neurol 2005, 18(5):574-580

8. Argyriou AA, Bruna J, Marmiroli P, Cavaletti G: Chemotherapy-induced peripheral neurotoxicity (CIPN): an update. Crit Rev Oncol Hematol 2012, 82(1):51-77.

9. Grisold W, Cavaletti G, Windebank AJ: Peripheral neuropathies from chemotherapeutics and targeted agents: diagnosis, treatment, and prevention. Neuro Oncol 2012, 14(Suppl 4):iv45-iv54.

10. Argyriou AA, Iconomou G, Kalofonos HP: Bortezomib-induced peripheral neuropathy in multiple myeloma: a comprehensive review of the literature. Blood 2008, 112(5):1593-1599.

11. Johnson DC, Corthals SL, Walker BA, Ross FM, Gregory WM, Dickens NJ, Lokhorst HM, Goldschmidt H, Davies FE, Durie BG, Van Ness B, Child JA, Sonneveld P, Morgan GJ: Genetic factors underlying the risk of thalidomide-related neuropathy in patients with multiple myeloma. J Clin Oncol 2011, 29(7):797-804.

12. Lao L, Hamilton GR, Fu J, Berman BM: Is acupuncture safe? A systematic review of case reports. Altern Ther Health Med 2003, 9(1):72-83.

13. Ernst $E$, White AR: Prospective studies of the safety of acupuncture: a systematic review. Am J Med 2001, 110(6):481-485.

14. Macpherson H, Scullion A, Thomas KJ, Walters S: Patient reports of adverse events associated with acupuncture treatment: a prospective national survey. Qual Saf Health Care 2004, 13(5):349-355.

15. Su JW, Lim CH, Chua YL: Bilateral pneumothoraces as a complication of acupuncture. Singapore Med J 2007, 48(1):e32-e33.

16. Peuker $\mathrm{E}$, Gronemeyer D: Rare but serious complications of acupuncture: traumatic lesions. Acupunct Med 2001, 19(2):103-108.

17. Chang SA, Kim YJ, Sohn DW, Park YB, Choi YS: Aortoduodenal fistula complicated by acupuncture. Int J Cardiol 2005, 104(2):241-242.

18. Shiflett SC, Schwartz GE: Effects of acupuncture in reducing attrition and mortality in HIV-infected men with peripheral neuropathy. Explore (NY) 2011, 7(3):148-154 
19. Phillips KD, Skelton WD, Hand GA: Effect of acupuncture administered in a group setting on pain and subjective peripheral neuropathy in persons with human immunodeficiency virus disease. J Altern Complement Med 2004, 10(3):449-455.

20. Zhang C, Ma YX, Yan Y: Clinical effects of acupuncture for diabetic peripheral neuropathy. J Tradit Chin Med 2010, 30(1):13-14.

21. Tong Y, Guo H, Han B: Fifteen-day acupuncture treatment relieves diabetic peripheral neuropathy. J Acupunct Meridian Stud 2010, 3(2):95-103.

22. Wang YP, Ji L, Li JT, Pu JQ, Liu FJ: Effects of acupuncture on diabetic peripheral neuropathies. Zhongguo Zhen Jiu 2005, 25(8):542-544.

23. Abuaisha BB, Costanzi JB, Boulton AJ: Acupuncture for the treatment of chronic painful peripheral diabetic neuropathy: a long-term study. Diabetes Res Clin Pract 1998, 39(2):115-121.

24. Jiang H, Shi K, Li X, Zhou W, Cao Y: Clinical study on the wrist-ankle acupuncture treatment for 30 cases of diabetic peripheral neuritis. J Tradit Chin Med 2006, 26(1):8-12.

25. Wong R, Sagar S: Acupuncture treatment for chemotherapy-induced peripheral neuropathy-a case series. Acupunct Med 2006, 24(2):87-91.

26. Donald GK, Tobin I, Stringer J: Evaluation of acupuncture in the management of chemotherapy-induced peripheral neuropathy. Acupunct Med 2011, 29(3):230-233.

27. Schroeder S, Meyer-Hamme G, Epplee S: Acupuncture for chemotherapyinduced peripheral neuropathy (CIPN): a pilot study using neurography. Acupunct Med 2012, 30(1):4-7.

28. Xu WR, Hua BJ, Hou W, Bao YJ: Clinical randomized controlled study on acupuncture for treatment of peripheral neuropathy induced by chemotherapeutic drugs. Zhongguo Zhen Jiu 2010, 30(6):457-460.

29. Zhao ZQ: Neural mechanism underlying acupuncture analgesia. Prog Neurobiol 2008, 85(4):355-375.

30. Han JS: Acupuncture and endorphins. Neurosci Lett 2004, 361(1-3):258-261.

31. Mittleman E, Gaynor JS: A brief overview of the analgesic and immunologic effects of acupuncture in domestic animals. J Am Vet Med Assoc 2000, 217(8):1201-1205.

32. Schroder S, Liepert J, Remppis A, Greten JH: Acupuncture treatment improves nerve conduction in peripheral neuropathy. Eur J Neurol 2007, 14(3):276-281.

33. Atkinson TM, Mendoza TR, Sit L, Passik S, Scher HI, Cleeland C, Basch E: The Brief Pain Inventory and its "pain at its worst in the last 24 hours" item: clinical trial endpoint considerations. Pain Med 2010, 11(3):337-346.

34. Kaptchuk TJ: Placebo studies and ritual theory: a comparative analysis of Navajo, acupuncture and biomedical healing. Philos Trans R Soc Lond B Biol Sci 2011, 366(1572):1849-1858.

35. Kaptchuk TJ, Kelley JM, Conboy LA, Davis RB, Kerr CE, Jacobson EE, Kirsch I, Schyner RN, Nam BH, Nguyen LT, Park M, Rivers AL, McManus C, Kokkotou E, Drossman DA, Goldman P, Lembo AJ: Components of placebo effect: randomised controlled trial in patients with irritable bowel syndrome. BMJ 2008, 336(7651):999-1003.

36. Kaptchuk TJ, Stason WB, Davis RB, Legedza AR, Schnyer RN, Kerr CE, Stone DA, Nam BH, Kirsch I, Goldman RH: Sham device v inert pill: randomised controlled trial of two placebo treatments. BMJ 2006, 332(7538):391-397.

37. Trotti A, Colevas AD, Setser A, Rusch V, Jaques D, Budach V, Langer C, Murphy B, Cumberlin R, Coleman CN, Rubin P: CTCAE v3.0: development of a comprehensive grading system for the adverse effects of cancer treatment. Semin Radiat Oncol 2003, 13(3):176-181.

38. Dedman P, Al-Khafaji M, Baker K: A Manual of Acupuncture. East Sussex, UK: Journal of Chinese Medicine Publications; 1998.

39. Deng LY: Chinese Acupuncture and Moxibustion. Beijing: Foreign Languages Press; 1997.

40. Buschbacher RM, Prahlow ND: Manual of Nerve Conduction Studies. 2nd edition. New York: Demos Medical Publishing; 2005.

\section{doi:10.1186/1756-8722-7-41}

Cite this article as: Garcia et al:: Electroacupuncture for thalidomide/ bortezomib-induced peripheral neuropathy in multiple myeloma: a feasibility study. Journal of Hematology \& Oncology 2014 7:41.

\section{Submit your next manuscript to BioMed Central and take full advantage of:}

- Convenient online submission

- Thorough peer review

- No space constraints or color figure charges

- Immediate publication on acceptance

- Inclusion in PubMed, CAS, Scopus and Google Scholar

- Research which is freely available for redistribution

Submit your manuscript at www.biomedcentral.com/submit 